Supplement of Biogeosciences, 18, 39-53, 2021 https://doi.org/10.5194/bg-18-39-2021-supplement (C) Author(s) 2021. This work is distributed under the Creative Commons Attribution 4.0 License.

(c) (1)

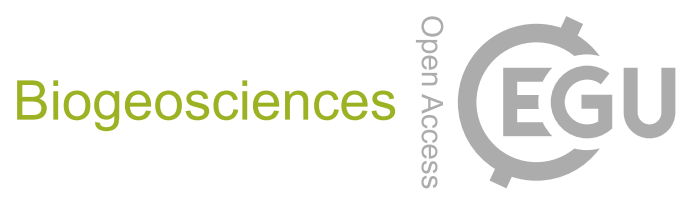

Supplement of

\title{
Vegetation modulates the impact of climate extremes on gross primary production
}

Milan Flach et al.

Correspondence to: Milan Flach (milan.flach@bgc-jena.mpg.de)

The copyright of individual parts of the supplement might differ from the CC BY 4.0 License. 


\section{Case Studies}

To illustrate the range of relative drought and heat anomalies, we report on different high and low impact extreme events in our data base in the following. For each of the events we show a figure with 5 maps, each showing the extent of the extreme event and the integrated imapct on (a) GPP, (b) the event duration, (c) the affected ecosystems (1: forest, 2: agriculture, 3: other), (d) average surface moisture conditions during the event, as well as (e) average temperature during the event. The latter two panels illustrate the range of temperatures and surface moisture conditions, one can observe during extreme events globally.

\section{Case Study: compounding European drought and heatwave 2003}

The event is most commonly known as European heatwave 2003 (classified here as compounding drought and heatwave). It started in April, peaked on the 14th of July and finished in September with a maximal duration of 104 days (Figure 1). The affected volume was $33 \cdot 10^{6} \mathrm{~km}^{2} \mathrm{~d}$. Total reduction in GPP is estimated here as $-11 g C m^{-2} m_{o n t} h^{-1}$, which is less than reported in (Ciais et al. 2005) (-28 $\left.g C m^{-2} m_{o n t h}{ }^{-1}\right)$. Differences can be seen especially for forested ecosystems in the low mountain ranges (Vosges, Thuringian Forests, Black Forest, Ardennes, Rhenish Massif, Taunus) and a larger area with enhanced productivity around the Alps (Figure 1). Comparing our results with eddy covariance site level data (Ciais et al. 2005, Reichstein et al. 2007) from literature reveals that site level data and Fluxcom-RS agree on the direction of the GPP anomalies for DE-Hai (both negative), FR-Hes (both negative), FR-Lbr (both positive), and disagree for BE-Vie, DE-Tha (both positive by FLUXCOM-RS, negative at the tower site).

Case Study: compounding drought and heatwave in the USA 2012

The US drought and heatwave in 2012 started in April, peaked on June, 29th, and ended mid October with a maximal duration of 144 days. The affected volume was $12 \cdot 10^{6} \mathrm{~km}^{2} \mathrm{~d}$. Total reduction in GPP is estimated here as $-15 \mathrm{gC} \mathrm{m}^{-2} \mathrm{month}^{-1}$. However, on average forests increase their productivity by $13 \%\left(22 \mathrm{gC} \mathrm{m}^{-2}\right.$ mont $\left.^{-1}\right)$. The one common affected tower site from literature (US-MMS) (Wolf et al. 2016) is in agreement with FLUXCOM-RS (both agree on a negative impact) (Figure 2).

Case Study: compounding Russian drought and heatwave 2010

The event is most commonly known as (western) Russian heatwave 2010. It is one of the most impacting events in our data base (Fig. 3, classified here as compounding drought and heatwave). It started in June, peaked on July, 19th, and ended in September with a maximal duration of 80 days. The 
affected volume was $87 \cdot 10^{6} \mathrm{~km}^{2} \mathrm{~d}$. The total reduction in GPP is estimated here as $72 \mathrm{TgC}$, roughly comparable to (Bastos et al. 2014) (90 $\mathrm{TgC}$ ). We estimated losses in agricultural ecosystems to be $22 \%$ compared to the normal GPP average, which is comparable e.g. to estimates from (Wegren 2010) (grain harvest reduction of one third). However, we also estimate forests to enhance their productivity by $5 \%$ during the event. We could not find eddy covariance tower based estimates of carbon losses in literature.

Case Study: compounding European drought and heatwave 2018

The summer drought and heatwave in Mid-Europe 2018 started in June, peaked on July, 24th and lasted until August (Fig. 4). It was associated with a relative reduction in GPP by $10 \%$ (6\%) in agricultural (other) ecosystems. However, forests on average still are still productive as usual $( \pm 0 \%)$. These differences between forests and agricultural ecosystems are also reported in (Buras et al. 2019).

\section{Case Study: drought in Brazil 2012}

The drought in Brazil 2012 is another high impact event in our data base (Fig. 5). It started in April, peaked on May, 2nd, and lasted until September, with a maximum duration of 136 days. The affected volume was $24 \cdot 10^{6} \mathrm{~km}^{2} \mathrm{~d}$. Total reduction in carbon is estimated to be $-36 \mathrm{TgC}$. We are not aware of any tower or model based comparison of this number. The affected area is in agreement with maps published in (Marengo et al. 2013).

Case Study: compounding drought and heatwave at the Horn of Africa 2009

The drought at the greater Horn of Africa 2009 (Fig. 6 is classified here as compounding drought and heatwave). It started in July, peaked on August, 14th, and lasted until September. The affected volume was $23 \cdot 10^{6} \mathrm{~km}^{2} \mathrm{~d}$. Total reduction in GPP is estimated to be $20 \mathrm{TgC}$. There have been no eddy covariance towers in the affected region 2009, but the event is also reported in (Nicholson 2014).

\section{Case Study: compounding Indian drought and heatwave 2009}

The Indian heatwave 2009 is one of the least impacting (most enhanced GPP) events in our data base (Fig. 7). It started in May, peaked at August, 1st. and lasted until September. The affected volume of the event is $45 \cdot 10^{6}$ $k m^{2} d$. The peak of the event is 53 days before peak of the growing season. Although it is classified as a relative drought and heatwave, there is still water available for large areas during the event (Fig. 7 (d), 25\%, mean surface moisture during event). The conditions are associated with increased productivity by $6 \%(12 \%)$ in agricultural (forest) ecosystems and enhances 
total GPP by $13 \mathrm{TgC}$ compared to the other years. The event presents the strongest enhancement of GPP of a single event in our data base. We can find warnings related to drought reduced agricultural yields in literature (Neena et al. 2011). However, the Organisation for Economic Co-operation and Development (OECD) reports a $4 \%$ increase in the wheat production for India 2009 (OECD 2009).

\section{Case Study: Siberian heatwave 2011}

The Siberian heatwave in 2011 another example of the least impacting event in our data base (Fig. 8). It starts in May, peaks on June, 1st. and lasts until the end of June. The affected volume is $31 \cdot 10^{6} \mathrm{~km}^{2} \mathrm{~d}$. The peak of the heatwave is 41 days before peak growing season and it is has a maximum duration of 40 days, but shows a rather short duration for large parts of the event (Fig. 8). Water seems to be available during the heatwave (27\%, mean surface moisture during event). These conditions are associated with an enhancement of GPP by $34 \%(29 \%)$ in forests (other) ecosystems (43 $\mathrm{TgC}$ ) in other ecosystems. The event illustrates that a relative detection of drought and heat anomalies also includes events which are not severely affecting vegetation but can be beneficial for vegetation especially in Northern latitudes for which temperature and surface moisture conditions are still moderate.

\section{Case Study: compounding drought and heatwave in China 2011}

The drought (and heatwave) in Southern China 2011 is one of the events in our data base (Fig. 9) showing strong differences among a East-West gradient. It starts in July 2006, peaks on August, 21th and lasts until September. The affected volume is $38 \cdot 10^{6} \mathrm{~km}^{2} \mathrm{~d}$. Maximum duration is 72 days, 31 days after peak growing season. Eastern agricultural $(-7 \mathrm{TgC})$ areas are strongly affected by the event in contrast to other ecosystems $(+7 \mathrm{TgC})$ in the western parts of the affected area. These dipole-like structures can also be seen in maps of mean temperature and surface moisture during the event. Forests are partly associated with enhanced productivity, especially in regions with high temperatures and available surface moisture. This is interpreted as a positive reaction to the available radiation during the heatwave part of the event (Song et al. 2019).

\section{Case Study: compounding eastern European drought and heatwave 2015}

The summer drought and heatwave affecting Europe with a focus on East Europe in 2015 started in June, peaked on August, 2nd and lasted until September. It was relatively short lasting for most of the affected area $(<20$ days), and probably therefore affecting productivity not so strongly (Total 
impact: $-0.5 \mathrm{TgC}$ agriculture, $+5 \mathrm{TgC}$ forests), although the affected volume was comparable to other high-impact extreme events $\left(21 \cdot 10^{6} \mathrm{~km}^{2} \mathrm{~d}\right)$.

Case Study: compounding Amazon drought and heatwave 2010

The Amazon drought 2010 is one of the well-known high-impact events of the last decade. It is classified here as a compounding drought and heatwave. It started in October 2009, peaked on January, 25th and lasts until March with a maximal duration of 184 days. It affected both, forests, and other ecosystems which reduced GPP by 7\%, 9\% respectively. The affected volume $\left(107 \cdot 10^{6} \mathrm{~km}^{2} \mathrm{~d}\right)$ is among the highest in our data base (Fig. 11). 


\section{References}

Bastos, A., Gouveia, C. M., Trigo, R. M. \& Running, S. W. (2014). Analysing the spatio-temporal impacts of the 2003 and 2010 extreme heatwaves on plant productivity in Europe, Biogeosciences 11(13): 3421-3435.

Buras, A., Rammig, A. \& Zang, C. S. (2019). Quantifying impacts of the drought 2018 on european ecosystems in comparison to 2003, Biogeosciences Discussions 2019: 1-23.

URL: https://www.biogeosciences-discuss.net/bg-2019-286/

Ciais, P., Reichstein, M., Viovy, N., Granier, A., Ogée, J., Allard, V., Aubinet, M., Buchmann, N., Bernhofer, C., Carrara, A., Chevallier, F., De Noblet, N., Friend, A. D., Friedlingstein, P., Grünwald, T., Heinesch, B., Keronen, P., Knohl, A., Krinner, G., Loustau, D., Manca, G., Matteucci, G., Miglietta, F., Ourcival, J. M., Papale, D., Pilegaard, K., Rambal, S., Seufert, G., Soussana, J. F., Sanz, M. J., Schulze, E. D., Vesala, T. \& Valentini, R. (2005). Europe-wide reduction in primary productivity caused by the heat and drought in 2003, Nature 437(7058): 529-533.

Marengo, J. A., Alves, L. M., Soares, W. R., Rodriguez, D. A., Camargo, H., Riveros, M. P. \& Pabló, A. D. (2013). Two Contrasting Severe Seasonal Extremes in Tropical South America in 2012: Flood in Amazonia and Drought in Northeast Brazil, Journal of Climate 26(22): 9137-9154.

Neena, J. M., Suhas, E. \& Goswami, B. N. (2011). Leading role of internal dynamics in the 2009 Indian summer monsoon drought, Journal of Geophysical Research 116: D13103.

Nicholson, S. E. (2014). Journal of Arid Environments, Journal of Arid Environments 103(c): 71-79.

OECD (2009). Oecd data: Crop production, In: https://data.oecd.org/ agroutput/crop-production.htm accessed on July, 4th 2019.

Reichstein, M., Ciais, P., Papale, D., Valentini, R., Running, S., Viovy, N., Cramer, W., Granier, A., Ogée, J., Allard, V., Aubinet, M., Bernhofer, C., Buchmann, N., Carrara, A., Grünwald, T., Heimann, M., Heinesch, B., Knohl, A., Kutsch, W., Loustau, D., Manca, G., Matteucci, G., 
Miglietta, F., Ourcival, J.-M., Pilegaard, K., Pumpanen, J., Rambal, S., Schaphoff, S., Seufert, G., Soussana, J. F., Sanz, M. J., Vesala, T. \& Zhao, M. (2007). Reduction of ecosystem productivity and respiration during the European summer 2003 climate anomaly: a joint flux tower, remote sensing and modelling analysis, Global Change Biology 13(3): 634-651.

Song, L., Li, Y., Ren, Y., Wu, X., Guo, B., Tang, X., Shi, W., Ma, M., Han, X. \& Zhao, L. (2019). Divergent vegetation responses to extreme spring and summer droughts in Southwestern China, Agricultural and Forest Meteorology 279: doi: 10.1016/j.agrformet.2019.107703.

Wegren, S. K. (2010). Food Security and Russia's 2010 Drought, Eurasian Geography and Economics 51: 1-17.

Wolf, S., Keenan, T. F., Fisher, J. B., Baldocchi, D. D., Desai, A. R., Richardson, A. D., Scott, R. L., Law, B. E., Litvak, M. E., Brunsell, N. A., Peters, W. \& van der Laan-Luijkx, I. T. (2016). Warm spring reduced carbon cycle impact of the 2012 US summer drought, Proceedings of the National Academy of Sciences 113(21): 5880-5885. 
(a) GPP anomaly

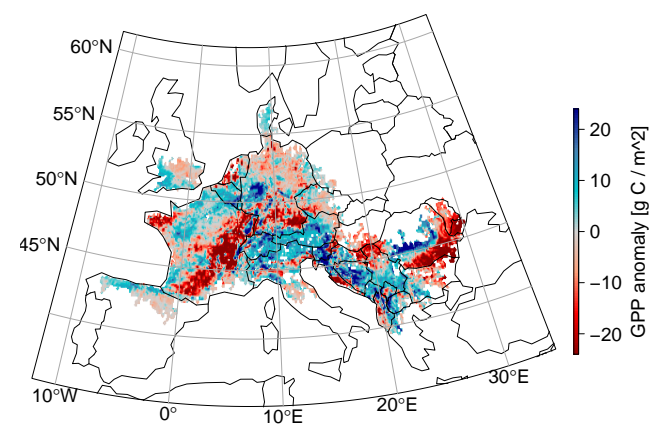

(c) Ecosystems

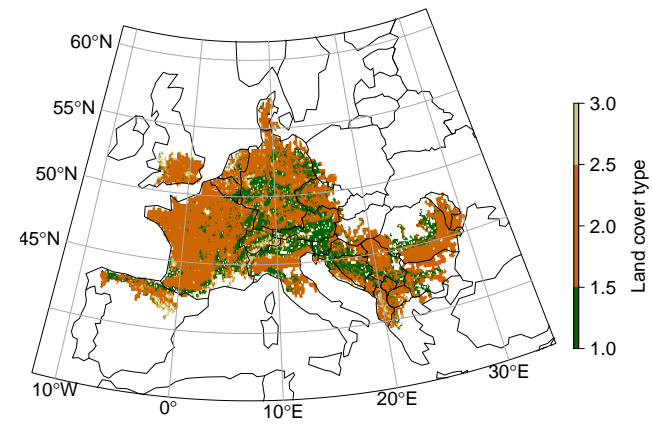

(b) Duration

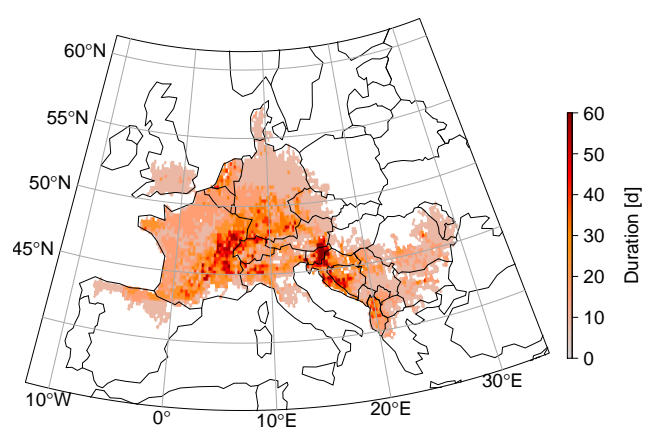

(d) Surface moisture

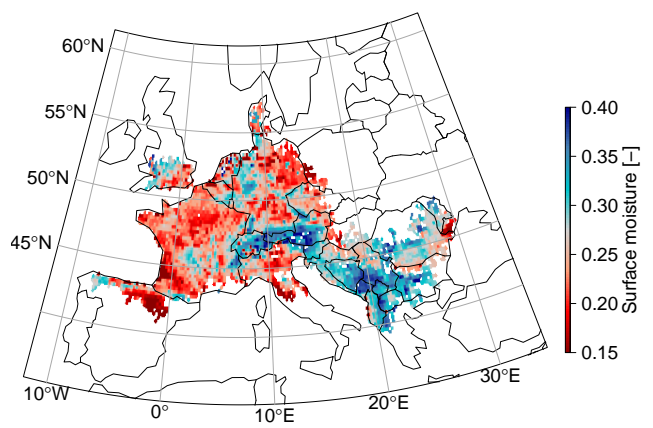

(e) Temperature

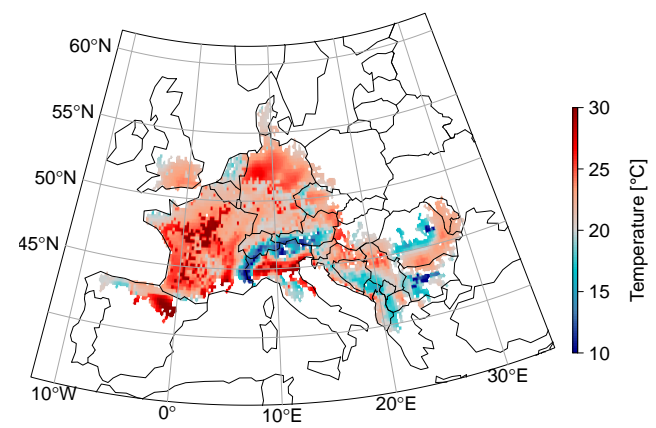

Figure 1: (a) Impact on GPP anomaties, (b) duration, (c) affected ecosystem types, (d) surface moisture conditions, and (e) temperature conditions associated with the European heatwave 2003. 
(a) GPP anomaly

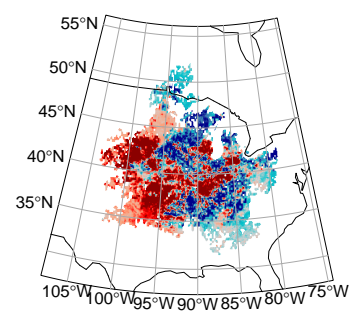

(c) Ecosystems

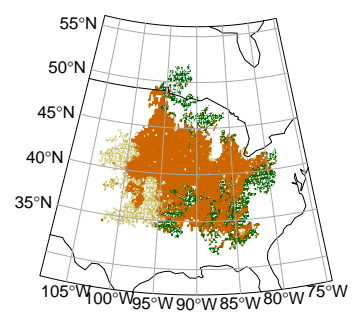

(e) Temperature

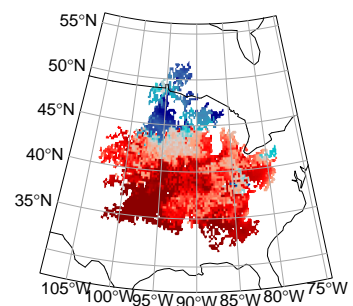

(b) Duration
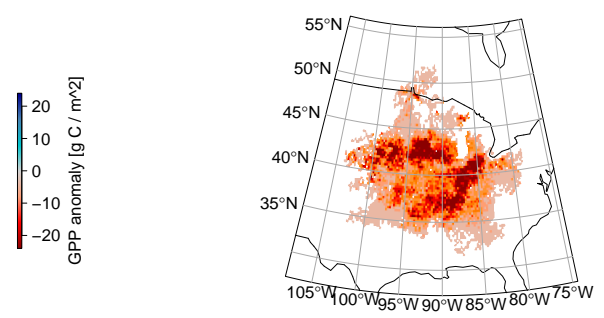

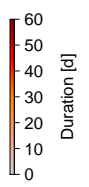

(d) Surface moisture
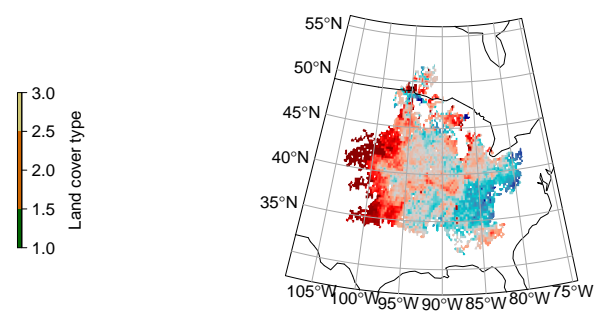

Figure 2: (a) Impact on GPP anomalies, (b) duration, (c) affected ecosystem types, (d) surface moisture conditions, and (e) temperature conditions associated with the US 2012 drought and heatwave. 
(a) GPP anomaly

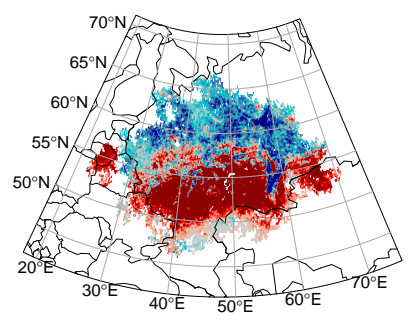

(c) Ecosystems

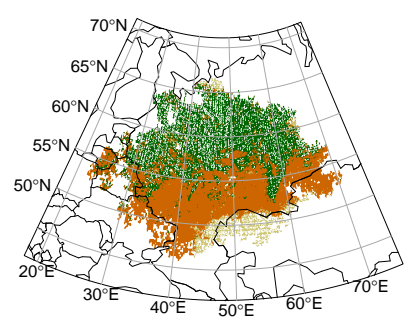

(e) Temperature

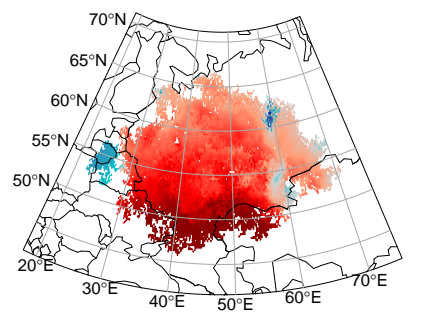

(b) Duration
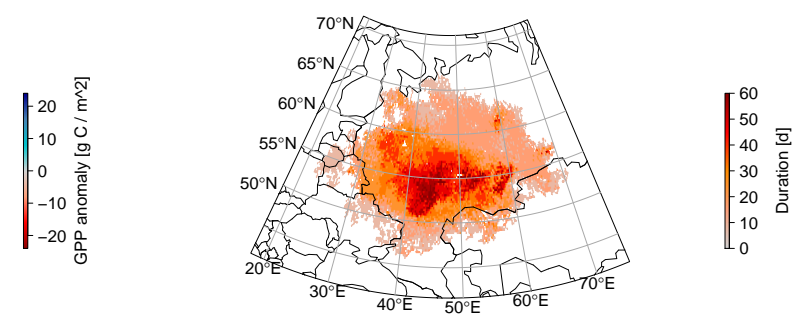

(d) Surface moisture

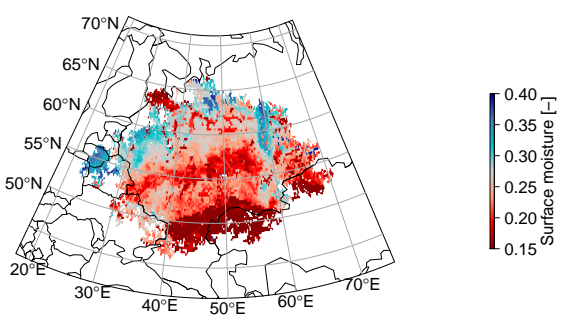

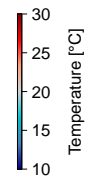

Figure 3: (a) Impact on GPP anomalies, (b) duration, (c) affected ecosystem types, (d) surface moisture conditions, and (e) temperature conditions associated with the Russian heatwave 2010. 
(a) GPP anomaly

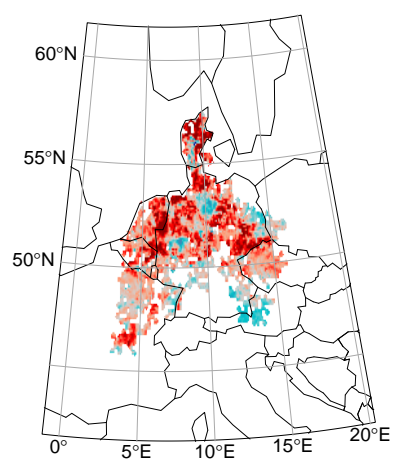

(c) Ecosystems

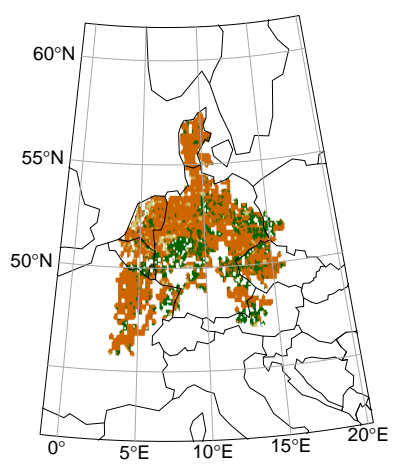

(e) Temperature

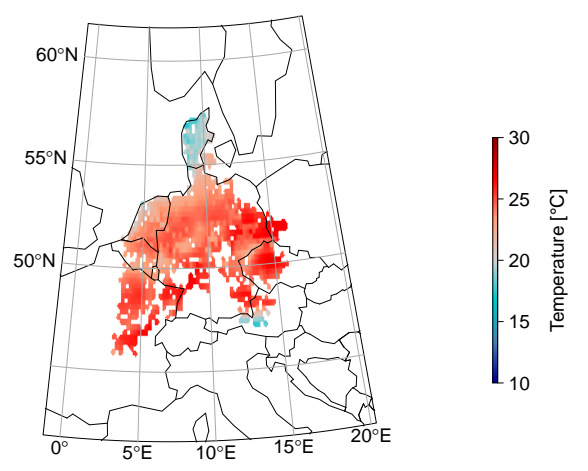

(b) Duration
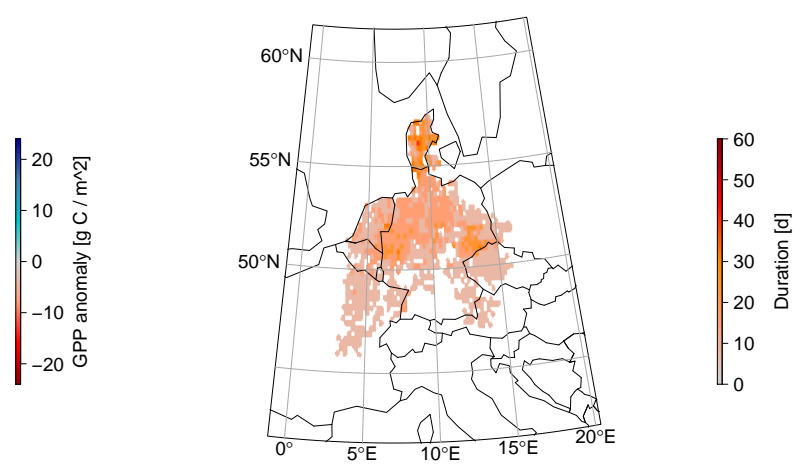

(d) Surface moisture

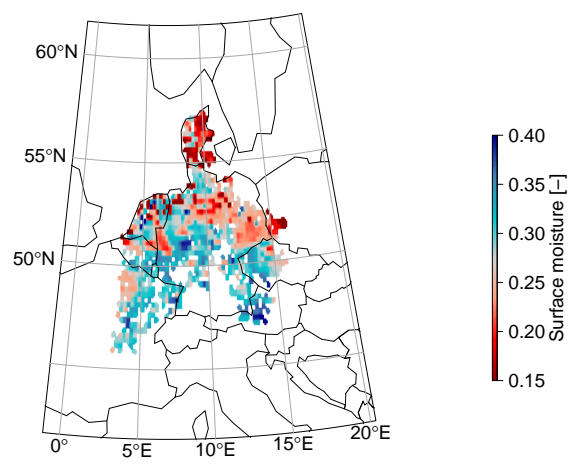

Figure 4: (a) Impact on GPP anomaljes, (b) duration, (c) affected ecosystem types, (d) surface moisture conditions, and (e) temperature conditions associated with the European heatwave 2018. 
(a) GPP anomaly

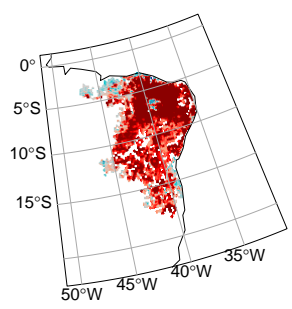

(c) Ecosystems

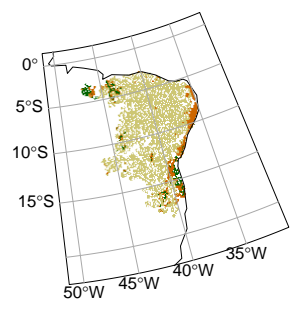

(e) Temperature

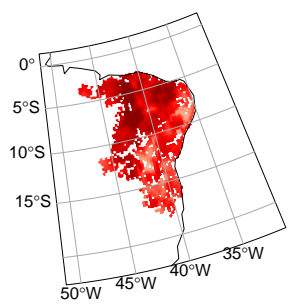

(b) Duration
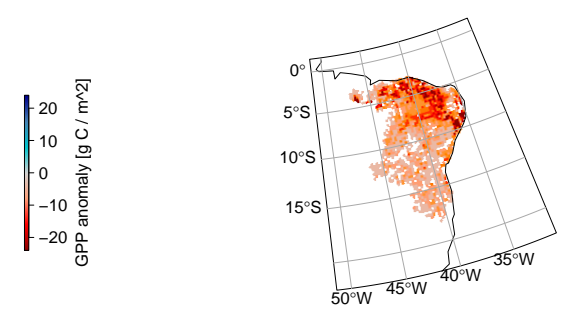

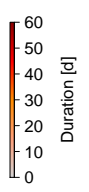

(d) Surface moisture
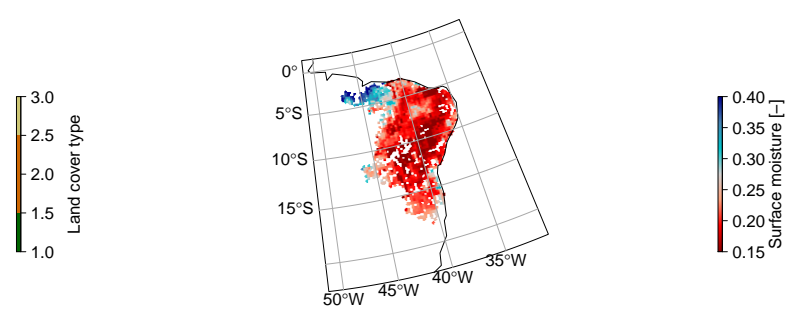

Figure 5: (a) Impact on GPP anomalies, (b) duration, (c) affected ecosystem types, (d) surface moisture conditions, and (e) temperature conditions associated with the drought in Brazil 2012. 
(a) GPP anomaly

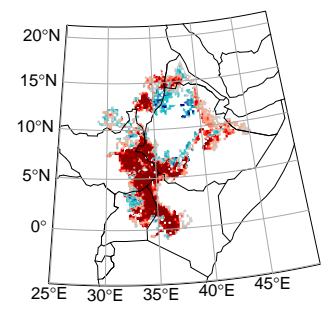

(c) Ecosystems

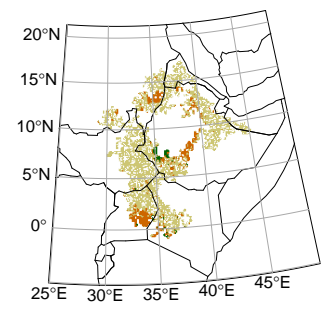

(e) Temperature

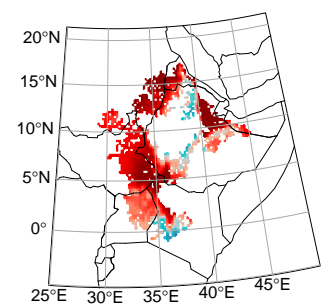

(b) Duration

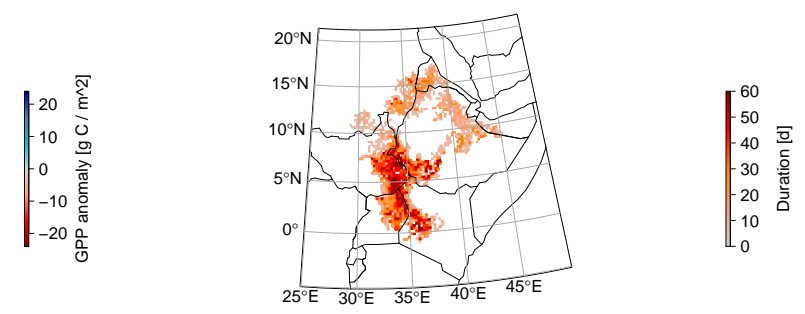

(d) Surface moisture
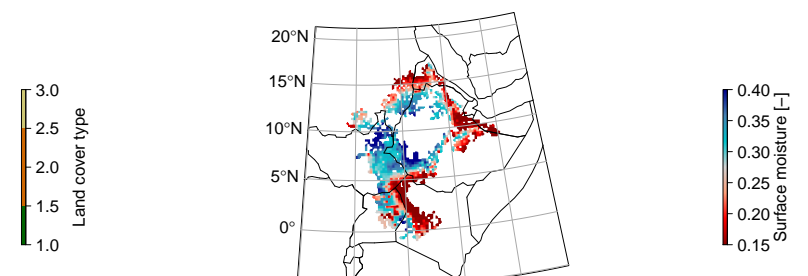

Figure 6: (a) Impact on GPP anomalies, (b) duration, (c) affected ecosystem types, (d) surface moisture conditions, and (e) temperature conditions associated with the drought at the greater Horn of Africa 2009. 
(a) GPP anomaly

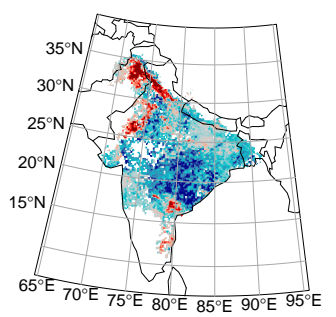

(c) Ecosystems

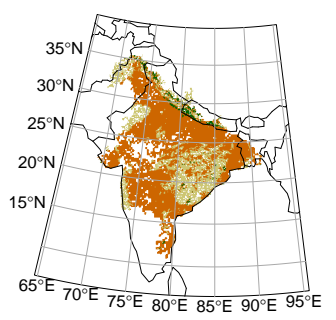

(e) Temperature

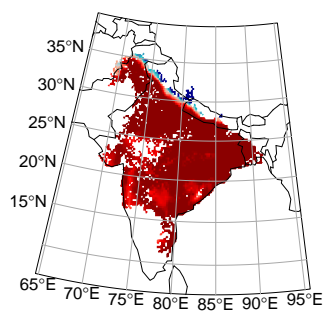

(b) Duration
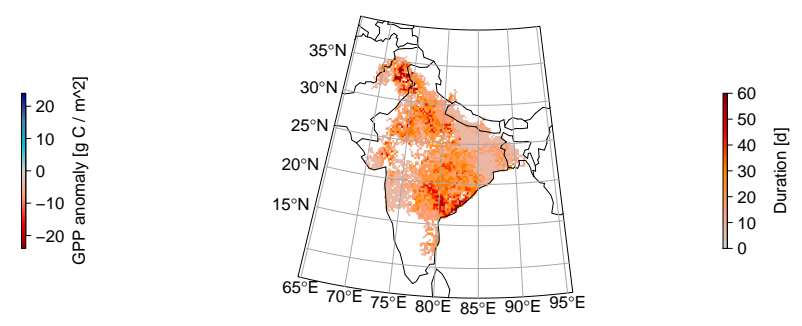

(d) Surface moisture

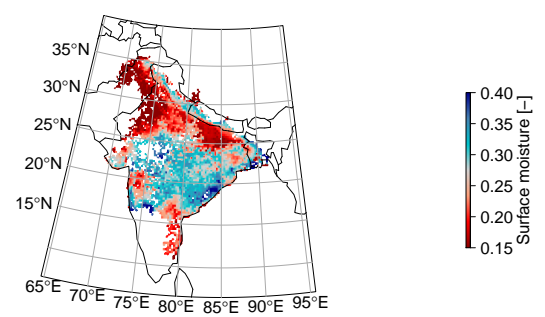

Figure 7: (a) Impact on GPP anomalies, (b) duration, (c) affected ecosystem types, (d) surface moisture conditions, and (e) temperature conditions associated with the Indian heatwave 2009. 
(a) GPP anomaly

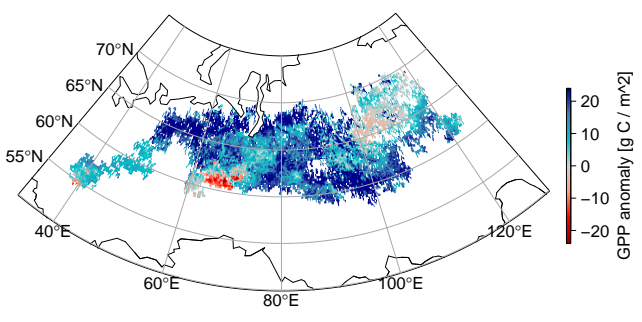

(c) Ecosystems

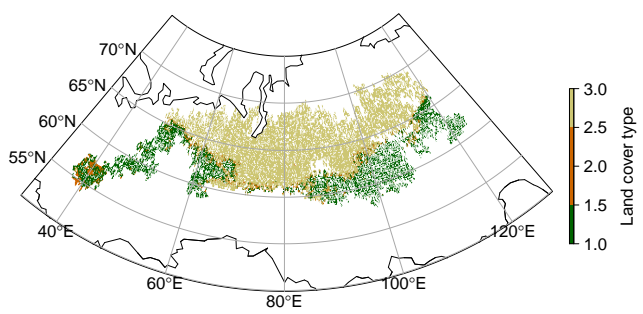

(e) Temperature

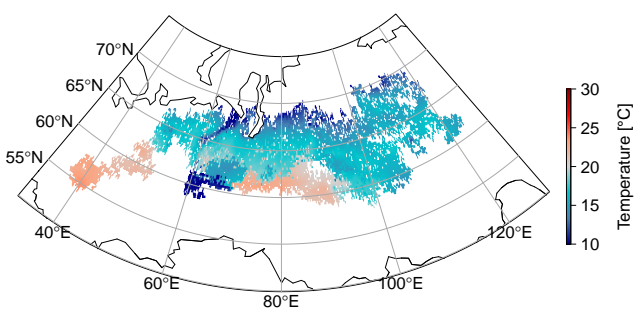

(b) Duration

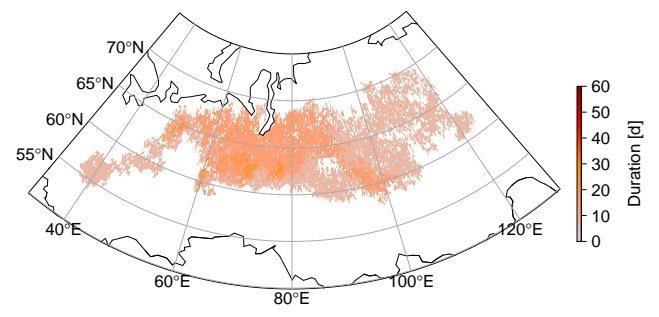

(d) Surface moisture

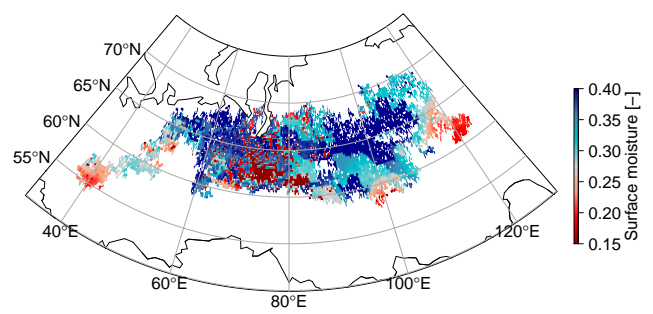

Figure 8: (a) Impact on GPP anomalies, (b) duration, (c) affected ecosystem types, (d) surface moisture conditions, and (e) temperature conditions associated with the Siberian heatwave 2011. 
(a) GPP anomaly

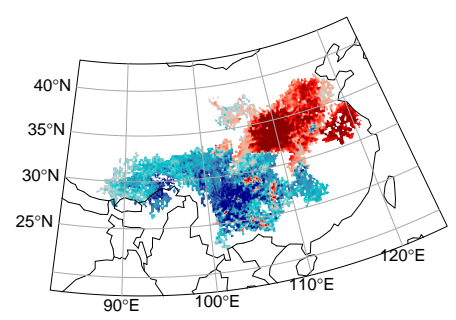

(c) Ecosystems

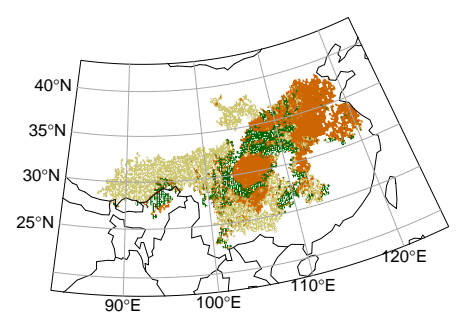

(e) Temperature

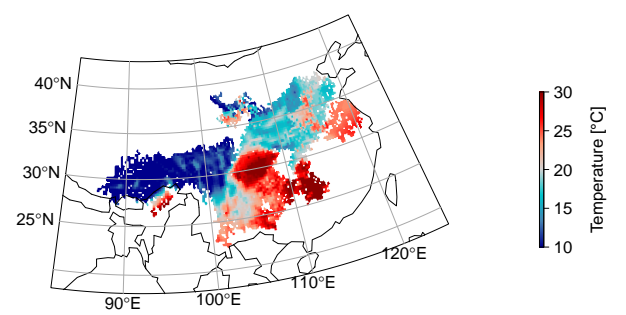

(b) Duration
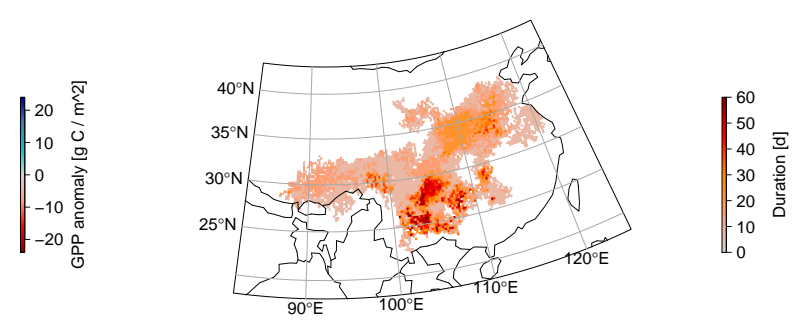

(d) Surface moisture

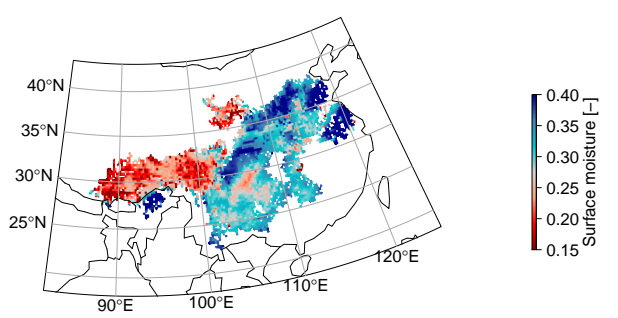

Figure 9: (a) Impact on GPP anomalies, (b) duration, (c) affected ecosystem types, (d) surface moisture conditions, and (e) temperature conditions associated with the China drought 2011. 
(a) GPP anomaly

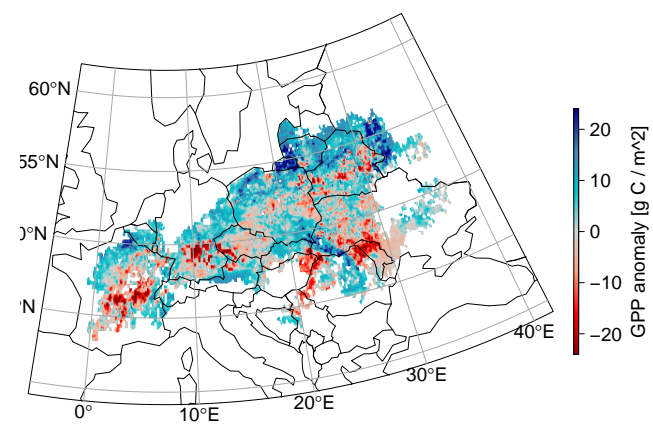

(c) Ecosystems

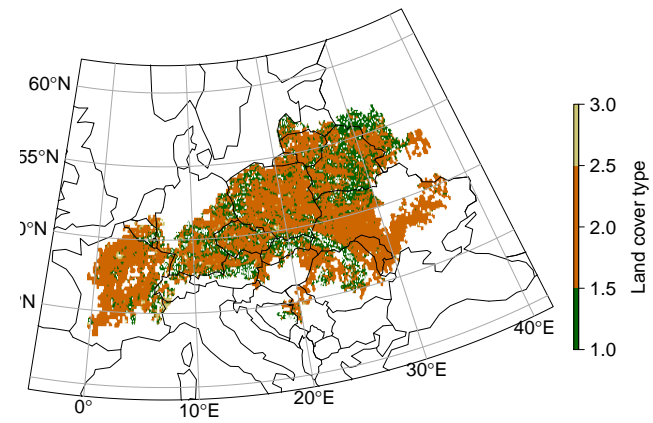

(b) Duration

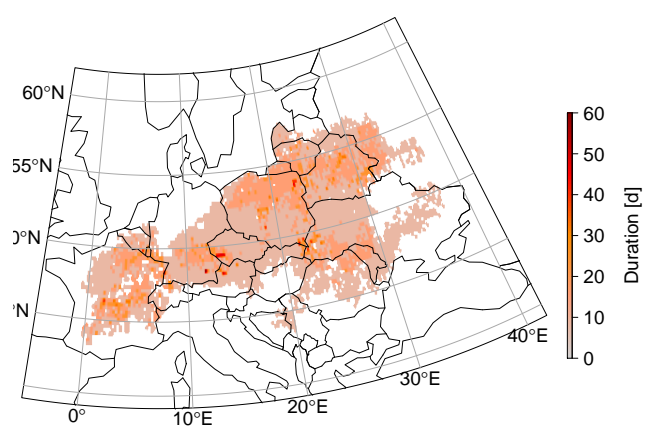

(d) Surface moisture

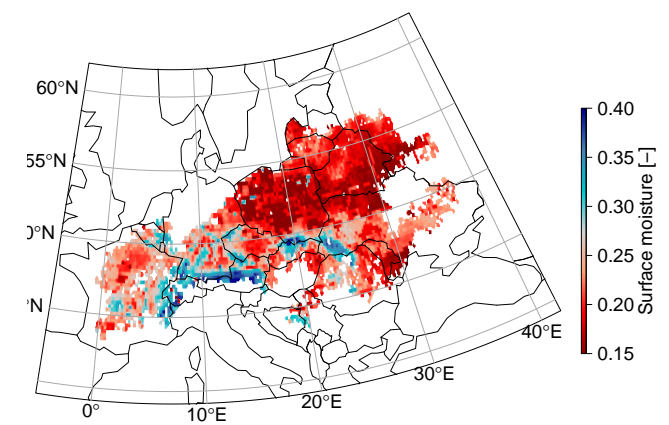

(e) Temperature

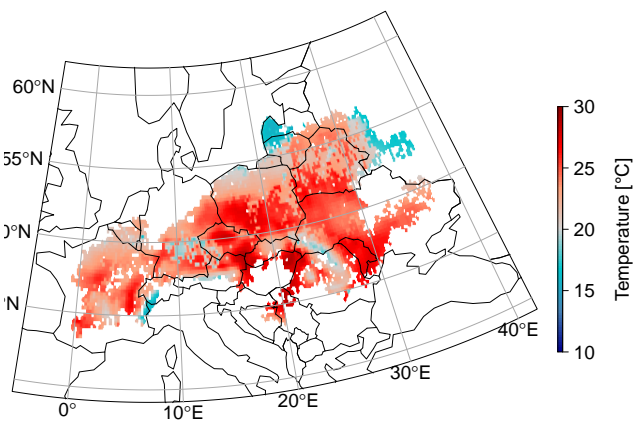

Figure 10: (a) Impact on GPP anomaies, (b) duration, (c) affected ecosystem types, (d) surface moisture conditions, and (e) temperature conditions associated with the Drought and heatwave in East Europe 2015. 
(a) GPP anomaly

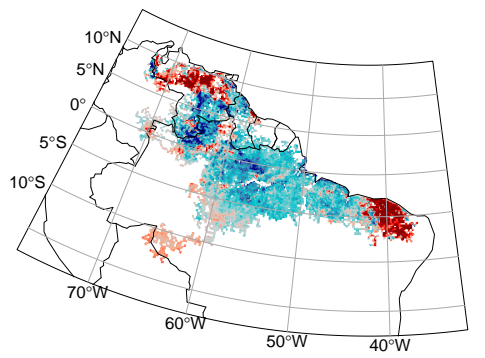

(c) Ecosystems

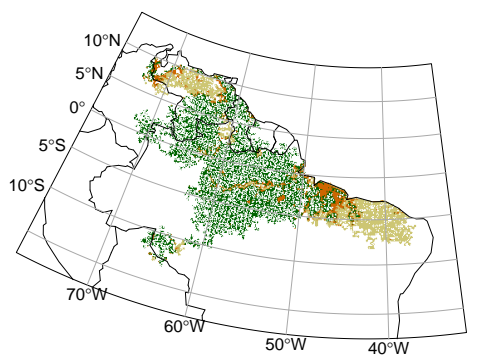

(e) Temperature

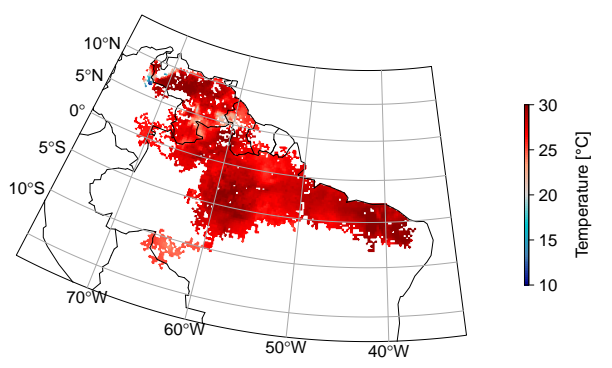

(b) Duration

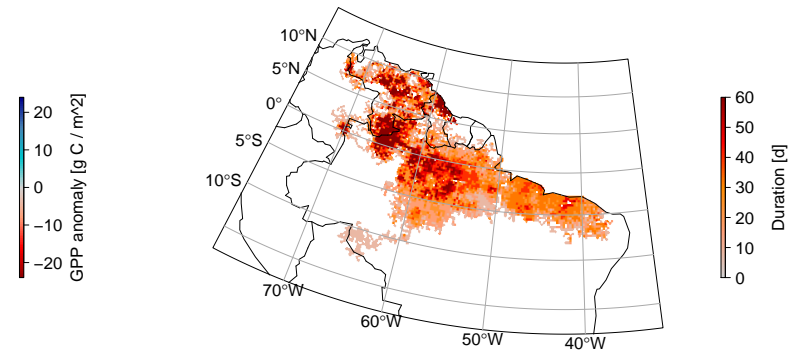

(d) Surface moisture

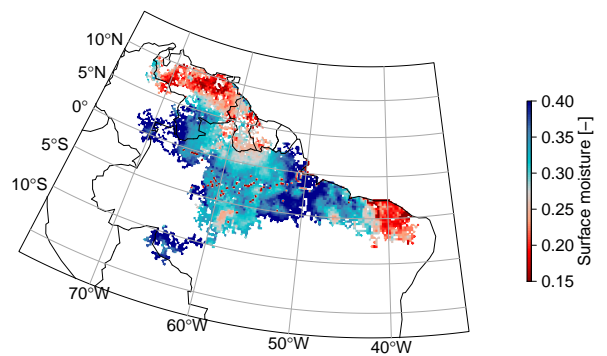

Figure 11: (a) Impact on GPP anomalies, (b) duration, (c) affected ecosystem types, (d) surface moisture conditions, and (e) temperature conditions associated with the Amazon drought 2010. 